\title{
Obituary: Adrian Laycock
}

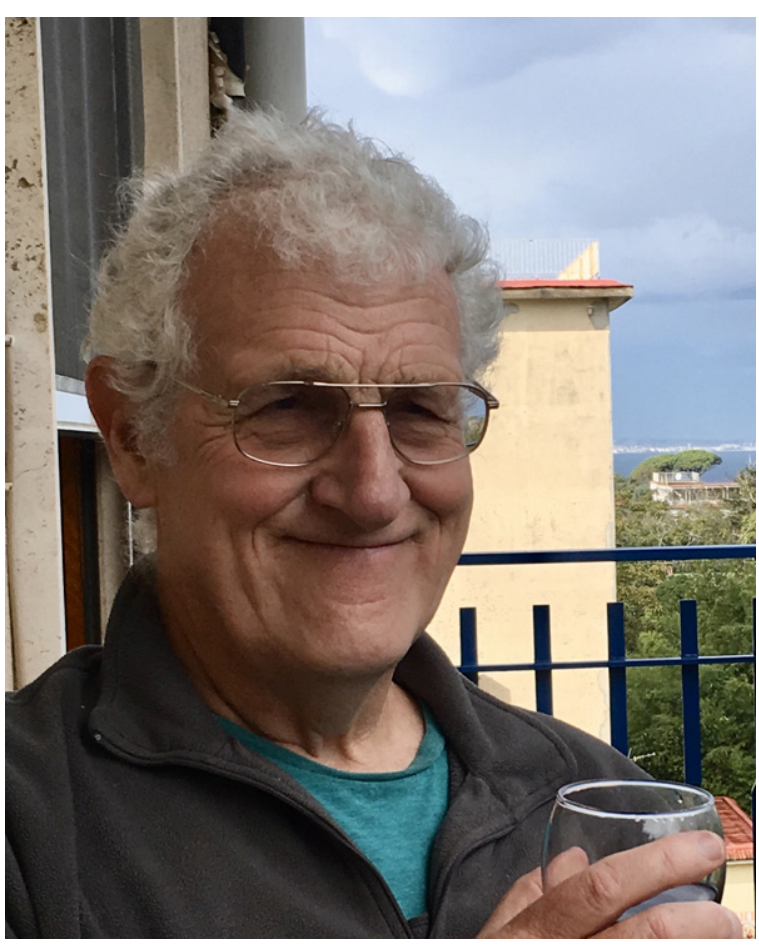

Figure 1. Adrian Laycock, 1947-2019

It is we great sadness that we report the death of Adrian Laycock in August of this year.

Adrian was a Fellow of the Institution of Civil Engineers (ICE) and had been a member for 54 years.

Qualified in both civil and agricultural engineering, Adrian devoted his life to improving that of others. Professionally this was expressed initially through working in over 30 countries, where his passion for water engineering and desire to make a far-reaching and lasting impact on peoples' lives left a tangible legacy of new and revitalised irrigation networks, and latterly by applying those hard-earned skills to the generation of hydropower in Scotland.

After qualifying from Aberdeen University (Aberdeen, Scotland) in 1969, Adrian gained experience in Zambia, Malawi and what was then Rhodesia, where his work in planning dams and water resources inspired him to study further, culminating in a Master's degree in soil and water engineering from Silsoe College (Bedfordshire, UK) in 1973.

He had extensive experience in the design, planning, construction and management of irrigation and water resource development projects, with substantial computerised design expertise in canal systems, earth dams, weirs and related hydraulic structures. He was a specialist in troubleshooting and rehabilitating malfunctioning irrigation schemes, with an appreciation of the international problems of agriculture, sociology, environmental effects, economics and institutional organisation. He gave numerous talks and lectures on various aspects of irrigation, many at the ICE.

His intellect, ability to think laterally and to challenge convention commanded respect from fellow professionals, and more importantly, resulted in the creation of innovative solutions to challenging engineering problems. His strength of personality was instrumental in forming a single design team from a medley of companies, cultures and disciplines.

These attributes shone through his work in Pakistan in the 1990s, where he was responsible for the detailed design, preparation of contract documents and construction supervision on the Swabi Salinity Control and Reclamation Project, and the Pehur High Level Canal developments. The Pehur High Level Canal, which Adrian designed, is thought to be the world's largest true parabolic canal. Indeed, Adrian was primarily responsible for the introduction of pre-cast parabolic canals to India, Indonesia and Pakistan, and for the large-scale automation, large parabolic canals and low-pressure pipeline distribution systems in Pakistan and Sudan.

His engineering achievements are there for all to see and are too numerous to list. They include tunnelling into the Tarbela Dam (Khyber Pakhtunkhwa, Pakistan), rehabilitating old canals, creating new irrigation and drainage systems, and developing a paperless design office that produced thousands of AutoCAD drawings automatically from LISP routines.

On top of this, Adrian found time to edit News \& Views, and, in line with his ability to get things done, added getting it printed and circulated to his editing role. He was also the author of the much sought-after book Irrigations Systems Design Planning and Construction published by the Centre for Agriculture and Bioscience International in 2007.

Throughout his time working abroad, Adrian maintained his love of music, squash and social interaction and made a positive impact on the lives of colleagues, many of whom became life-long friends, through his natural kindness, generosity, sense of humour and warm personality.

When family commitments brought him back to Scotland, the transition to hydropower was a natural one. His abilities - both in engineering and leadership - were very much in demand. Over the last ten years, Adrian Laycock Ltd, which he formed in 1983, has designed and supervised construction of over 50 hydropower schemes, from small community projects to $1 \mathrm{MW}$ schemes, across the length and breadth of Scotland.

A former colleague recently commented: 'Adrian's passion and knowledge of the hydro sector was both inspirational and reassuring to all of our clients. A testament to his ability is the fact that all these schemes were delivered on time, within budget and have outperformed the predicted revenue flows. He will certainly be greatly missed throughout the West Highlands'.

He will be missed indeed, and much more broadly than in Scotland which he came to call his home. Adrian used his technical abilities to make the world a better place. His abiding legacy is that he inspired many others to do the same.

Sandra Melville 